Особенности внутреннего убранства жилища народов Среднего Поволжья конца
$\mathrm{XIX}$ - первой половины XX веков

Краснощеков В.А.

ФГБОУ ВО «Поволжский государственный университет сервиса»,

Тольятти, Росийская Федерация.

(iD) https://orcid.org/0000-0003-0275-4490, e-mail: kulbiaka@yandex.ru

Резюме: В статье уделяется внимание внутреннему убранству жилищ Среднего Поволжья конца XIX - первой половины XX веков, которое, в силу обусловленных этнонациональных и историко-культурных фракторов, предположительно, обладает определенной специфрикой. Цель статьи - выявить особенности внутреннего убранства жилища народов Среднего Поволжья конца XIX - первой половины XX веков. Подчеркивается, что элементы интерьера, позволяют судить о духовной и материальной сферах жизнедеятельности их носителей.

Методы статьи основаны на сочетании культурологического, исторического (в сочетании со сравнительным) и системного подходов.

В результате изучения культуры народов, населяющих регион, литературы, посвященной анализу особенностей организации внутреннего пространства традиционного жилища народов Среднего Поволжья в исследуемый период, документов различного характера, данных полевых исследований, а также фондов музеев, делается вывод о том, что при неизбежном разнообразии внутреннего убранства жилищ народов Среднего Поволжья, наблюдается однотипность внутренней планировки жилого пространства. Отмечается взаимопроникновение национальных культур, выраженное в наличии общих черт в убранстве жилищ разнородных этнических групп, позволяющих говорить о региональной средневолжской культуре, нашедшей проявление в предметно-бытовой среде и устройстве интерьера.

Ключевые слова: Среднее Поволжье, традиционная культура, жилище, быт, интерьер, этническое взаимовлияние.

Для цитирования: Краснощеков В.А. Особенности внутреннего убранства жилища народов Среднего Поволжья конца XIX — первой половины XX веков // Этническая культура. - 2020. - № 2 (3). - C. 14-19. DOI:10.31483/r-75069.

\title{
Features of the Interior Environment of the Dwellings of the Peoples of the Middle Volga Region at the End of the XIX - the First Half of the XX Centuries
}

\author{
Vladimir A. Krasnoshchyokov \\ FSBEI of HE "Volga Region State University of Service", \\ Togliatti, Russian Federation. \\ https://orcid.org/0000-0003-0275-4490, e-mail: kulbiaka@yandex.ru
}

\begin{abstract}
The article pays attention to the interior environment of the dwellings of the Middle Volga region at the end of the 19th - first half of the 20th centuries, which due to ethnonational and historical and cultural factors, may have some specific features. The purpose of the article is to reveal the features of the interior environment of the dwellings of the peoples of the Middle Volga region at the end of the XIX - the first half of the XX centuries. It is emphasized that the interior elements allow us to judge the spiritual and material spheres of life of their carriers.

The methods of the article are based on a combination of cultural, historical (in combination with comparative) and systems approaches.

As a result of studying the culture of the peoples living in the region as well as literature devoted to the analysis of the peculiarities of the organization of the internal space of the traditional dwellings of the peoples of the Middle Volga region during the study, various documents, data from field studies, as well as museum funds, it is concluded that, with the inevitable variety of interior environment the dwellings of the peoples of the Middle Volga region, the same type of internal layout of the living space is observed. It is noted that one can observe the interpenetration of national cultures, expressed in the presence of common features in the interior of the dwellings of diverse ethnic groups, which makes it possible to talk about the regional Middle Volga culture, which is manifested in the object-household environment and design of interior.

Keywords: traditional culture, Middle Volga Region, housing, life, interior, ethnic mutual influence.

For citation: Krasnoshchyokov V.A. (2020). Features of the Interior Environment of the Dwellings of the Peoples of the Middle Volga Region at the End of the XIX - the First Half of the XX Centuries. Etnicheskaya kultura = Ethnic Culture, 2(3),
\end{abstract} 14-19. (In Russ.) DOI:10.31483/r-75069.

Введение

Формированию бытовой среды человека во все времена придавалось большое значение. Устройство быта, подбор и характер его элементов являются мерой самоопределения человека, где дом выступает как один из основных источников и передатчиков информации. Дом служил своеобразной «книгой и вместе с тем активно содействовал формированию представлений об эталонных связях в системе мир - человек» [2, с. 12-13].

Значительная часть традиционной культуры региона дошла до нас в виде предметов быта и обихода, элементов интерьера, что позволяет судить о духовной и материальной сферах жизнедеятельности их носителей. Внутреннее содержание дома, наличие и характер имеющихся в нем вещей является важной составной частью национальной повседневной культуры. В городской среде индустриального общества, нередко, только особенности внутреннего убранства жилища позволяют длительное время сохранять этническую уникальность.

Будучи полиэтничной в силу определенных исторических и экономических факторов, повседневная культура Среднего Поволжья ${ }^{1}$ в ее бытовом предметно-средовом выражении обладает этносоциальной 
спецификой, своей логикой исторического развития. При этом наблюдается взаимопроникновение и взаимодействие национальных культур, различные инонациональные заимствования, а также ряд общих черт культуры и быта разнородных этнических групп, позволяющих говорить о региональной средневолжской культуре, нашедшей проявление в предметно-бытовой среде и устройстве интерьера. В более же широком масштабе изучение истории Среднего Поволжья дает богатый материал для осмысления отечественной культуры в целом.

Культурные формы, нередко, носят синтетический характер, что соответствует общей концепции развития российской культуры, обладающей механизмами по продвижению наиболее удачных своих феноменов. В данной работе делается попытка найти подтверждение этому теоретическому положению на эмпирическом материале, связанном с традиционными элементами внутреннего убранства жилища, устройства быта и характера его элементов народов, проживающих на территории Среднего Поволжья.

Хронологические рамки исследования в основном охватывают конец XIX - первую половину XX века.

\section{Обзор литературы}

Большая часть использованной в ходе исследования литературы посвящена анализу особенности внутреннего убранства жилища народов Среднего Поволжья конца XIX - первой половины XX веков.

Изучение национальной специфики народов, населяющих регион в XVIII-XIX веках, и их культуры базировалось на трудах И. И. Лепехина [23] и М.Н. Рагозина [24]. Исследование традиционных народных предметов повседневного быта региона с точки зрения их символического содержания опиралось на работу советского и российского фольклориста, этнографа и антрополога А.К. Байбурина [2]. Источником фактического материала послужили публикации по истории дореволюционного и советского быта, собранные в работах П.В. Алабина [1], А.С. Говорова [10], В.А. Барадулина [3], Н.Ф. Мокшина [15], М.Н. Романовой и Л.Н. Щанкиной [26], а также А.К. Салмина [27], Д.Н. Сулеймановой [28] и М.В. Сульдинского [29], в которых описана бытовая и обрядовая стороны жизни, этнические взаимовлияния культуры народов региона.

При описании особенностей организации внутреннего пространства традиционного жилища региона (черты интерьера, меблировка) большую роль сыграла информация, содержащаяся в работах Л.В. Беловинского [4], Е.Э. Бломквист [5; 6] и О.А. Ганцкой [6].

При разработке темы были проанализированы архивные и опубликованные документы, данные полевых исследований и прикладные материалы: неопубликованные источники (архивные документы различного характера) в Российском государственном архиве древних актов (РГАДА, г. Москва); комплекс документов научного архива Института этнологии и антропологии им. Н.Н. Миклухо-Маклая Российской академии наук (ИЭА РАН, г. Москва), содержащий информацию об этнографических экспедициях на территории Среднего Поволжья в 1951-1967 гг; коллекции предметов быта традиционной повседневной культуры и деко- ративного искусства, представленные в экспозициях и хранящихся в фондах музеев: ГБУК «Самарский областной историко-краеведческий музей (СОИКМ) им. П.В. Алабина» (г. Самара); МБУ «Краеведческий музей г. о. Сызрань»; МБУК «Димитровградский краеведческий музей» (г. Димитровград, Ульяновская обл.); МБУК г. о. Тольятти «Городской музейный комплекс «Наследие» (экомузей)» (Самарская обл.); ФГБУК «Всероссийский музей декоративно-прикладного и народного искусства» (ВМДПНИ, г. Москва); МБУК «Сергиевский историко-краеведческий музей» муниципального района Сергиевский (Самарская обл.).

\section{Материалы и методы}

В ходе исследования использовалось сочетание нескольких методологических подходов: культурологического (в котором материальная составляющая повседневной культуры - предметы быта и домашнего обихода, интерьер - рассматриваются как показатель условий, способствующих совершенствованию жизнедеятельности человека, с точки зрения реализации способностей его как субъекта культуры); исторического (предполагающего изучение особенностей внутреннего убранства жилища народов, населяющих Среднее Поволжье, в широкой исторической перспективе) и системного (позволяющего всесторонне охватить традиционную повседневную культуру Среднего Поволжья, представить ее как нечто самостоятельное, обладающее системными качествами). Исторический подход дополняет идея самоорганизации, успешно развитая синергетикой.

Для изучения общего и специфического в быту и убранстве жилища этносов Среднего Поволжья применялся сравнительно-исторический метод, позволяющий раскрыть сущность явлений в процессе их развития и реконструкции внутреннего убранства жилища в исследуемый период (конец XIX - первая половина $\mathrm{XX}$ века) путем описания, сопоставления и сравнения.

\section{Результаты исследования}

Внутренняя планировка традиционного жилого помещения в Среднем Поволжье конца XIX - первой половины XX веков зависела от трех факторов: расположения печи, переднего угла и направления устья печи. Исследователи выделяют четыре типа внутренней планировки жилого дома: северно-среднерусский, восточный южнорусский, западный южнорусский и западнорусский [6, с. 138]. А поскольку в Среднем Поволжье проживали выходцы из разных областей европейской части России [1, с. 73; 23, с. 163], то в регионе встречаются все вышеперечисленные типы внутренней планировки жилища. С некоторым преобладанием северо-среднерусской планировки [17, л. 11/об, 12/об, 21, 23, 24/об, 40; 18, л. 15/об, 17, 43, 44/об; 19, л. 27, 67, 28, 31-34].

Неизменными считались следующие правила расположения печи: «1) чтобы печь помещалась в углу диагонально противоположном тому, в котором помещаются иконы, а последние чтобы были видны тотчас же, как закроется входная дверь; 2) чтобы печь помещалась у глухой стены. Таким образом, печь помещалась при входе в избу возле той стены, которая выходит не на двор, так как именно эта стена и делается глухой» [21, л. 52]. 
Помимо традиционных русских печей были дополнительные прямоугольные или цилиндрические кирпичные печи-голанки [11, с. 376], они же «подтопки» $[19$, л. 4/об], с толстыми наружными стенками и хорошо развитым вертикальным дымооборотом, которые клались «... около русской печи, ... замыкая чуланную перегородку, которую называют «стойник» [22, л. 8]. Часто роль такой перегородки выполняла занавеска [22, л. 7/об]. В Среднем Поволжье преобладали голанки цилиндрической формы.

Расписывать печь в Среднем Поволжье было не принято. Единственными элементами декора печи являлись припечные доски, закрывавшие устье топки. И то их украшали росписью в основном переселенцы с Верхней Волги и Прикамья [3, с. 62, 151]. Более распространены были чугунные заслонки, с заводским штампованным орнаментом [13, №2807].

Рядом с печью висел рукомойник - глиняный или металлический кувшин. Под ним стояла деревянная, бондарной работы, лохань или корчага для грязной воды и помоев. Позднее появился металлический рукомойник со стержнем, выполняющим роль запирающего клапана. Лохань же стали заменять тазами.

Посуды в избе было немного. Она располагалась в «бабьем» углу у печи на полках вдоль стен [19, л. 3-69; 20, л. 1-31]. В этом углу находилась широкая «стряпущая» [4] судная лавка, идущая от печи вдоль стены. Она располагалась выше других лавок в доме, чтобы удобно было работать стоя, имела внизу полки, закрывающиеся створчатыми или раздвижными дверцами или занавеской или просто доской. Тем самым представляя собой невысокий напольный ящик-шкаф, который служил для хранения посуды и продовольствия [11, с. 613]. Со временем он трансформировался в знакомый нам кухонный стол.

Над судной лавкой крепился посудный шкафчик «разинька», без дверцы, от чего и получил свое название» [22, л. 7/об], а также «ложкарник», на котором висели ложки и черпаки [20, л. $13,16,21]$.

Лавки шли вдоль стен, начиная от входа, и служили для сидения, спанья, хранения различных хозяйственных мелочей. Лавка, находившаяся около печки, называлась кутно́й или «припёком». На нее ставили ведра с водой, горшки, чугунки, укладывали только что выпеченный хлеб. Лавка, которая шла вдоль стены, где расположена дверь, называлась пороговая. Она использовалась женщинами в дополнение кухонному столу. С другой стороны двери устраивалась лавка, называемая «конек» [7, с. 101].

Другим видом мебели была переносная скамья. Скамьи были шире лавок, до 1,4 метров шириною, длиною делались до 3 метров; на одном конце их приделывалось возвышение, называемое приголовником или подголовником. Подголовник мог быть и переносным. На скамьях не только сидели, но и спали.

Обеденный стол был обычно значительных размеров, с соотношением сторон 1:2 и 1:5 [16, №2606], в расчете на большую семью, и, как правило, из дуба.

Практически в каждом доме в центре, недалеко от голанки, висела колыбель - детская люлька (зыбка). Она крепилась к потолку на вставленный в потолочную балку (матицу) шест. Колыбель украшалась ро- списью, токарными деталями, фигурными вырезами в досках или резьбой [9, КП 15646, 22526, 26162; 25, №100]. Люльки встречались полностью деревянные, выполненные из досок, включая дно (северорусский вариант). Другой вид люлек представлял собой раму из деревянных брусков, к которой крепилось матерчатое или плетеное изо льна, лыка дно (средне- и южнорусский вариант). Такую люльку называли пяльчатой. Для Среднего Поволжья характерен свой оригинальный тип люлек, сочетающий в себе особенности вышеупомянутых вариантов: каркас из досок, выполненный столярным способом и матерчатое дно. Сверху люльку покрывали цветным вышитым покрывалом, старой юбкой или одеялом [16, №1663; 14, КП 5809].

Колыбели имели национальные особенности. Так, например, в мордовских семьях встречалась люлька, представлявшая собой корзину, в которую была положена подушка [20, л. 20]. Встречались колыбели из луба, «наподобие продолговатого лукошка, которое веревкой прикрепляется к гибкому рычагу, вставленному где-нибудь в отверстие над печью», что позволяло использовать гибкость рычага и раскачивать колыбель в вертикальной плоскости [22, л. 9].

Для замеса теста употреблялись деревянные корыта $[12$, КП-1090; 14, НВ 626] и большие чаны. Также в корытах рубили овощи, и использовали их для мытья белья. Воду носили ведрами, кумганами, корчагами [19, л. 3-69; 20, л. 1-31].

На женской половине около печи располагался деревянный сундук. Сундуки в исследуемый период были обязательной принадлежностью избы. В них хранили одежду, холсты и домашнюю утварь. Сундуки делали большие - до 2 м [16, КП-Д141 №4971; 30, КП 8929, ДМ 173; КП 9901, ДДР 591]. Укрепляли сундуки металлическими деталями, которые одновременно служили и украшениями [16, КП-Д114, №4664/2]. В металлических полосках делали прорезной орнамент. Затейливо украшали ручки, размещенные с боков сундука, личины замков и ключи [31]. Сундуки украшали и внутри геометрическим или растительным узором [16, КПД141, №4971].

Нужно сказать, что сундуки получили распространение в регионе только к концу XIX века. До этого их функцию выполняли различной формы лубочные короба [22, л. 10/об]. Например, архаичный предмет национального свадебного ритуала - мордовский свадебный короб цилиндрической формы, выдолбленный из ствола липы, верхняя половина которого оформлялась трехгранновыемчатой резьбой геометрического орнамента с условными изображениями человеческих фигур и орудий труда. Сверху короб покрывала крышка, которая запиралась на чугунную скобу ключом [30, КП 10507 , № ДМ 187, КП 10508, № ДМ 188; 8, ДП 537].

Внутренняя же планировка жилища у мордвы была под стать среднерусской «...с тем отличием, что сбоку печи, в стороне шестка $[11$, с. 650] имелся котел, в котором приготовляли пищу» [24, с. 49]. В летнее время котел выносился на улицу, под навес. У мокши встречалась и южнорусская планировка, при которой печь стояла в дальнем углу избы. Для мордовских изб были характерны полати над дверью. У мокши встречался дощатый настил перед печью [26, с. 150] высотой 25-30 см 
от пола. Вдоль передней стены устраивались нары для сна, которые застилались войлочными покрывалами. Внутри нар хранилась одежда, украшения, деньги. Полок, в отличие от русского жилища, было мало.

Декоративно-художественное оформление мордовского жилища, как, впрочем, и русского и чувашского, носило ярко выраженный знаковый характер, тесно связанный как с древними языческими верованиями и магическими заклинаниями, так и с семантикой самих внешних границ дома, призванных защитить его обитателей от негативного воздействия внешнего мира. Весьма разработанное в религиозных верованиях мордвы обожествление, как самого жилища, так и его отдельных зон, границ и даже локативов, а также локализация собственно божеств (в общем, она совпадает с локализацией домового в русской избе) [15].

В конце XIX века внутреннее убранство эрзянского жилища «...стало фактически подобным русскому дому, и только мокшанские строения сохраняли ряд архаических черт» [31, с. 7]. Типологически близкие русской избе аналоги консервировали в своем архитектурном облике и внутреннем устройстве некоторые традиционные для мордвы черты. Например, наличие асимметрично расположенного окна на главном фасаде, которое помещалось ближе к одному из углов избы, так как другой угол занимала печь и др.

В чувашском жилище начала XX века «в избах по стенам стоят неподвижные лавки, обыкновенно плотно приделанные к стене, которые заменяют стулья и кровать. Кровать заменяют также полати, устраиваемые над самой дверью в заднем углу. Вообще чуваши очень скупы на мебель. У них мебели, кроме одного стола и одного стула, почти не имеется. В редких домах можно встретить шкафчик с посудой и несколько передвижных скамеек и табуретов; для сиденья служат просто чурбаки, обрубки бревен, небольшие кадушки, пудо́вки и даже вёдра. Над лавками выше окон тянутся полки, предназначенные для хранения различных мелких принадлежностей» [10, с. 52-53]. К середине же XX века интерьер чувашского жилища стал сходен с русским.

Жилище татар Среднего Поволжья делилось на две половины - переднюю и заднюю. Их соединяли сени, большей частью не крытые, где проходило домашнее богомолье. В передней половине более или менее зажиточного татарина-мещанина справа от входа в комнату располагалась большая печь [23, с. 149] и при ней котел, в котором варили пищу. На печи обычно стояли два медных, луженых кувшина, один - мужу, другой жене. Это было связано с конфессиональными запретами умываться из одного кувшина мужу и жене. Справа от печи висел занавес, аналог русского «стойника», за которым обедала хозяйка, когда у хозяина были гости. У печи, как правило, стоял самовар. За печью в углу большой медный таз для умывания. Далее, направо у стены за занавесом, располагались широкие глухие нары. Нары служили и кроватью, и ларем. Татары традиционно имели много перин и подушек, сшитых на русский манер. Особым уважением считалось посадить гостя на покрытую лавку [23, с. 148]. Сундуки являлись украшением дома и покрывались коврами. В задней избе производились повседневные работы, хранились кое-какие домашние пожитки, и летом здесь спали хозяева [24, с. 168-169].

\section{Обсуждение и заключение}

Опираясь на разноплановый материал, можно констатировать, что для композиции внутреннего убранства домов различных этносов Среднего Поволжья была характерна целостность и замкнутость пространства. При неизбежном разнообразии, вызванном притоком переселенцев из различных регионов европейской части России и традициями ими привносившимися, в сочетании с традициями благоустройства жилого пространства проживающего на территории региона коренного населения, наблюдается однотипность внутренней планировки жилища. Она тяготеет к среднерусской, сочетающей в себе расположение печи в углу, у «глухой» стены, диагонально противоположного «красному» углу, в котором помещаются иконы.

Ведущей цветовой гаммой жилища Среднего Поволжья была естественная древесная - золотисто-охристая (стены, деревянная мебель, с хорошо просматривающейся текстурой, посуда, утварь). В обстановке избы не было ни одного лишнего случайного предмета, каждая вещь имела свое строго определенное практическое и семантическое назначение, подкрепленное многовековой традицией.

В обычном рядовом интерьере региона главенствовал горизонтальный ритм мебели: сиденья лавок и скамеек, плоскости полок и полатей. Для сна использовали лавки, скамейки, сундуки с плоской крышкой, полати, встроенные и передвижные кровати - широкие лавки. Национальные черты в жилище Среднего Поволжья были представлены различного рода декором. В основном это резной орнамент, восходящий к истокам древнеславянской и финно-угорской языческой культуры, соединенный с элементами русской городской и помещичьей культуры.

Благодаря сбалансированности утилитарных и символических функций, можно говорить о жилище как о феномене региональной средневолжской культуры, нашедшей проявление в предметно-бытовой среде и устройстве интерьера через взаимопроникновение и взаимодействие национальных культур, различных инонациональных заимствований. И выразившейся в ряде общих черт культуры и быта внутреннего убранства жилища разнородных этнических групп Среднего Поволжья.

\section{Примечание}

1) Исторически границы Среднего Поволжья в исследуемый период менялись, как правило, вследствие причин административного характера. В данном контексте понятие «Среднее Поволжье» основывается на сочетании природно-географических, национально-экономических и этно-демографических факторов. Принимая во внимание эти условия, мы относим к Среднему Поволжью территорию, на которой в настоящее время расположены южная часть Республики Чувашия, Республика Татарстан, Республика Мордовия, Самарская, Ульяновская, Пензенская области, а также север Саратовской области. 


\section{Список литературы}

1. Алабин П. В. Двадцатипятилетие Самары, как губернского города: (историко-статистический очерк). - Самара: Издание Самарского статистического комитета, 1877. - 744 с.

2. Байбурин А.К. Жилище в обрядах и представлениях восточных славян. - М.: Наука, 1983. - 191 с.

3. Барадулин В.А. Искусство Прикамья. Народная роспись по дереву. - Пермь: Перм. книжное изд-во, 1987. - 184 с.

4. Беловинский Л.В. Изба и хоромы: Из истории русской повседневности. - М.: Профиздат, 2002. - 352 с.

5. Бломквист Е.Э. Крестьянские постройки русских, украинцев и белорусов (поселения, жилища и хозяйственные строения) // Восточнославянский этнографический сборник. Т. 31. - М.: АН СССР, 1956. - С. 3-458.

6. Бломквист Е.Э. Типы русского крестьянского жилища середины XIX - начала XX в. / Е.Э. Бломквист, О.А. Ганцкая // Русские: Историко-этнографический атлас: Земледелие. Крестьянское жилище. Крестьянская одежда (сер. XIX - начало XX в.). - М.: Наука, 1967. - С. 131-165.

7. Военно-статистическое обозрение Российской империи. Т. 5. Ч. 3: Самарская губерния. - СПб.: Тип. Деп. Ген. Штаба, 1853. - 185 с.

8. ГБУК «Мордовский республиканский музей изобразительных искусств им. С.Д. Эрьзи» (г. Саранск) [Электронный ресурс]. - Режим доступа: http://erzia-museum.ru/ru/

9. ГБУК «Самарский областной историко-краеведческий музей (СОИКМ) им. П.В. Алабина» (г. Самара) [Электронный ресурс]. - Режим доступа: http://www.alabin.ru/

10. Говоров А. С. Ивановка: монографическое описание села Екатериновской волости Самарской губернии. Самара: Тип. Селькредсоюза, 1926. - 98 с.

11. Даль В.И. Толковый словарь живого великорусского языка. в 4 т. Т. 1. - СПб.: Изд-во М. О. Вольфа, 1880. - 723 с.

12. МБУК «Димитровградский краеведческий музей» (г. Димитровград, Ульяновская обл.) [Электронный ресурс]. - Режим доступа: http://museum.dimitrovgrad.ru/?page_id=59

13. МБУК «Сергиевский историко-краеведческий музей» муниципального района Сергиевский (Самарская обл.) [Электронный ресурс]. - Режим доступа: http://www.muzei163.ru/

14. МБУК г. о. Тольятти «Городской музейный комплекс «Наследие» (экомузей)» (Самарская обл.) [Электронный pecypc]. - Режим доступа: http://musnasl.ru/index_pc.html

15. Мокшин Н.Ф. Религиозные верования мордвы. - Саранск: Морд. кн. изд-во, 1998. - 244 с.

16. МБУ «Краеведческий музей г. о. Сызрань» (Самарская обл.). Основной фонд. Научно-вспомогательный фонд.

17. Научный архив ИЭА РАН. Ф. 35. Оп. 1. Д. 509.

18. Научный архив ИЭА РАН. Ф. 35. Оп. 1. Д. 510.

19. Научный архив ИЭА РАН. Ф. 35. Оп. 1. Ед. хр. 2895.

20. Научный архив ИЭА РАН. Ф. 47. ОП. 12. Д. 1012.

21. Научный архив ИЭА РАН. Ф. ОЛЕАЭ. Д. 92.

22. Научный архив ИЭА РАН. Ф. ОЛЕАЭ. Д. 100.

23. Полное собрание ученых путешествий по России 1818-1825 гг. Т. ІІІ. Записки Академика И.И. Лепехина. Ч. 1. - СПб.: Императорская Академия Наук, 1821. - 540 с.

24. Рагозин В.И. Волга: в 3 т. Т. 3. От Оки до Камы. - СПб.: Типография К. Ретгер, 1881. - 496 с.

25. Районный Детский музей МУ УКиМП Администрации м. р. Нефтегорский (г. Нефтегорск, Самарская обл.) [Электронный ресурс]. - Режим доступа: http://www.museum.ru/m2963

26. Романова М.Н. Планировка и внутреннее обустройство жилища мордвы республики мордовия и Дальнего востока / М.Н. Романова, Л.Н. Щанкина // Исторические, философские, политические и юридические науки, культурология и искусствоведение. Вопросы теории и практики. Ч. 1. - Тамбов, 2011. - №4. - С. 148-152.

27. Салмин А.К. Семантика дома у чувашей. - Чебоксары: ЧГИГН, 1998. - 64 с.

28. Сулейманова Д. Н. Интерьер жилища волго-уральских татар: развитие и этнокультурная специфика: дис. ... канд. ист. наук. - Казань, 2007. - 289 с.

29. Сульдинский М.В. Семантика крестьянского жилища мордвы: Автореф. дис. ... канд. культурологии. - Саранск, 2007. - 20 с.

30. ФГБУК «Всероссийский музей декоративно-прикладного и народного искусства» (ВМДПНИ, г. Москва).

[Электронный ресурс]. - Режим доступа: http://www.vmdpni.ru/

31. Хозяйство и быт русских крестьян. Памятники материальной культуры. Определитель / А.С. Бежкович, С.К. Жегалова, А.А. Лебедева [и др.]. - М.: Советская Россия, 1959. - 254 с.

\section{References}

1. Alabin, P. V. (1877). Dvadtsatipiatiletie Samary, kak gubernskogo goroda: (istoriko-statisticheskii ocherk)., 744. Samara: Izdanie Samarskogo statisticheskogo komiteta.

2. Baiburin, A. K. (1983). Zhilishche v obriadakh i predstavleniiakh vostochnykh slavian [Dwelling in rites and representations of Eastern Slavs]., 191. Moscow: Nauka.

3. Baradulin, V. A. (1987). History of Kama area. Folk Wood-Painting., 184. Perm: Perm. knizhnoe izd-vo.

4. Belovinskii, L. V. (2002). Izba i khoromy: Iz istorii russkoi povsednevnosti. Moscow: Profizdat.

5. Blomkvist, E. E. (1956). Krest'ianskie postroiki russkikh, ukraintsev i belorusov (poseleniia, zhilishcha i khoziaistvennye stroeniia) [Peasant buildings of the Russians, Ukrainians, and Belorussians]. Vostochnoslavianskii etnograficheskii sbornik. Vol. 31, 3-458. Moscow: AN SSSR.

6. Blomkvist, E. E., \& Gantskaia, O. A. (1967). Tipy russkogo krest'ianskogo zhilishcha serediny XIX. Russkie: Istoriko-etnograficheskii atlas: Zemledelie. Krest'ianckoe zhilishche. Krest'ianskaia odezhda (ser. XIX, nachalo XX v.), 131-165. Moscow: Nauka. 
7. (1853). Military Statistical Review of the Russian Empire. Vol. 5. Ch. 3: Samarskaia guberniia., 185. St. Peterburg: Tip. Dep. Gen. Shtaba.

8. SBIC "Mordovskii respublikanskii muzei izobrazitel'nykh iskusstv im. S. D. Erzi" (g. Saransk). Retrieved from http://erzia-museum.ru/ru/

9. SBIC "Samarskii oblastnoi istoriko-kraevedcheskii muzei (SOIKM) im. Alabina, P. V.." (g. Samara). Retrieved from http://www.alabin.ru/

10. 1Govorov, A. S. (1926). Ivanovka., 98. Samara: Tip. Sel'kredsoiuza.

11. Dal, V. I. (1880). Tolkovyi slovar' zhivogo velikorusskogo iazyka. in 4 vol. Vol. 1., 723. Saint Petersburg: Izd-vo M. O. Vol'fa.

12. SBIC "Dimitrovgradskii kraevedcheskii muzei" (g. Dimitrovgrad, Ul'ianovskaia obl.). Retrieved from http:// museum.dimitrovgrad.ru/?page_id=59

13. SBIC "Sergievskii istoriko-kraevedcheskii muzei" munitsipal'nogo raiona Sergievskii (Samarskaia obl.). Retrieved from http://www.muzei163.ru/

14. SBIC of Togliatti "Gorodskoi muzeinyi kompleks "Nasledie" (ekomuzei)" (Samarskaia obl.). Retrieved from http://musnasl.ru/index_pc.html

15. Mokshin, N. F. (1998). Religioznye verovaniia mordvy., 244. Saransk: Mord. kn. izd-vo.

16. MBI "Kraevedcheskii muzei g. o. Syzran'" (Samarskaia obl.). Osnovnoi fond. Nauchno-vspomogatel'nyi fond.

17. Nauchnyi arkhiv IEA RAN. F. 35. Op. 1. D. 509.

18. Nauchnyi arkhiv IEA RAN. F. 35. Op. 1. D. 510.

19. Nauchnyi arkhiv IEA RAN. F. 35. Op. 1. Ed. khr. 2895.

20. Nauchnyi arkhiv IEA RAN. F. 47. Op. 12. D. 1012.

21. Nauchnyi arkhiv IEA RAN. F. OLEAE. D. 92.

22. Nauchnyi arkhiv IEA RAN. F. OLEAE. D. 100.

23. (1821). Polnoe sobranie uchenykh puteshestvii po Rossii 1818-1825 gg. T. III. Zapiski akademika Lepekhina, I. I.

Ch. 1., 540. St. Petersburg: Imperatorskaia Akademiia Nauk.

24. Ragozin, V. I. (1881). Volga., 496. St. Petersburg: Tipografiia K. Retger.

25. Raionnyi Detskii muzei MU UKiMP Administratsii m. r. Neftegorskii (g. Neftegorsk, Samarskaia obl.). Retrieved from http://www.museum.ru/m2963

26. Romanova, M. N., \& Shchankina, L. N. (2011). Planirovka i vnutrennee obustroistvo zhilishcha mordvy respubliki mordoviia i Dal'nego vostoka. Istoricheskie, filosofskie, politicheskie i iuridicheskie nauki, kul'turologiia i iskusstvovedenie. Voprosy teorii i praktiki. Ch. 1, 4, 148-152. Tambov.

27. Salmin, A. K. (1998). Semantika doma u chuvashei., 64. Cheboksary: ChGIGN.

28. Suleimanova, D. N. (2007). Inter'er zhilishcha volgo-ural'skikh tatar: razvitie i etnokul'turnaia spetsifika., 289. Kazan'.

29. Sul'dinskii, M. V. (2007). Semantika krest'ianskogo zhilishcha mordvy: Avtoref. dis., 20. Saransk.

30. FSBIC "Vserossiiskii muzei dekorativno-prikladnogo i narodnogo iskusstva" (VMDPNI, g. Moskva). Retrieved from http://www.vmdpni.ru/

31. Bezhkovich, A. S., Zhegalova, S. K., \& Lebedeva, A. A. (1959). Khoziaistvo i byt russkikh krest'ian. Pamiatniki material'noi kul'tury. Opredelitel'., 254. Moscow: Sovetskaia Rossiia.

Информация об авторе
Краснощеков Владимир Александрович - канд. ист. наук, ФГБОУ ВО «Поволжский государственный университет сервиса», Тольятти, Российская Федерация
Information about the author

Vladimir A. Krasnoshchyokov - candidate of historical sciences, associate professor of FSBEI of HE "Volga Region State University of Service", Togliatti, Russian Federation 